\title{
Os paradoxos entre a democracia e o dizer-verdadeiro
}

\author{
The paradoxes between democracy and tell-true
}

\section{Márcio Alves da Fonseca}

Professor Doutor do Departamento de Filosofia e do Programa de Estudos Pós-Graduados em Filosofia da Pontifícia Universidade Católica de São Paulo (PUC-SP), São Paulo, SP - Brasil, e-mail: marciofons@uol.com.br

\section{Resumo}

Ao retomar parte do estudo realizado por Michel Foucault sobre a noção de parrhesia (dizer-verdadeiro) no curso Le gouvernement de soi et des autres, o artigo pretende explicitar alguns aspectos da abordagem do filósofo acerca da parrhesia em suas relações com a democracia antiga. Se nas primeiras aulas desse curso do Collège de France o estudo sobre a parrhesia é conduzido pela interpretação da tragédia ĺon, na qual se identifica o momento da fundação mítica da parrhesia democrática, a análise dos discursos proferidos por Péricles aos cidadãos atenienses - relatados por Tucídides em sua Guerra do Peloponeso -, em um momento crucial da guerra da cidade contra os lacedemônios, permitirá a Foucault discorrer sobre aquilo que considera ser o núcleo paradoxal das implicações entre o dizer-verdadeiro e a democracia antiga. Apoiando-se em tais análises de Foucault, o artigo sugere a necessidade de um pensamento atual acerca da democracia que considere - para além dos problemas tradicionais da representatividade, da liberdade, da autonomia dos indivíduos e do exercício do poder político - o vínculo necessário e, por vezes, ambíguo, entre a democracia e o discurso verdadeiro.

Palavras-chave: Parrhesia. Democracia. Verdade. Michel Foucault. 


\section{Abstract}

This paper aims to clarify some aspects of Michel Foucault's approach about the "tell-true" in its relations with the ancient democracy, by taking up part of the study made by the French philosopher on the notion of parrhesia in the course Le gouvernement de soi et des autres. If the first lectures of the course at the Collège de France on parrhesia is conducted by the interpretation of the tragedy lon, in which Foucault identifies the mythical foundation of Athenian democracy parrhesia, by the analysis of the speeches given by Pericles to the Athenians - reported by Thucydides in his Peloponnesian War - in a crucial moment in the city's war against the Lacedaemonians, Foucault discuss the paradoxical core of the implications between "tell-true" and ancient democracy. Relying on such analysis of Foucault, the paper suggests the need for current thinking about democracy consider - in addition to the traditional problems of representative government, freedom, individual autonomy and the exercise of political power - the necessary link, sometimes ambiguous, between democracy and true discourse.

Keywords: Parrhesia. Democracy. Truth. Michel Foucault.

Os dois últimos anos do ensinamento de Michel Foucault em sua cátedra do Collège de France realizam, em conjunto, uma reconstituição histórica da noção de parrhesia na cultura e no pensamento antigos. No percurso que vai do "momento de fundação lendária do dizer-verdadeiro da democracia ateniense" (GROS, 2008, p. 353), identificado na tragédia euripidiana Íon, às considerações sobre o uso do termo nos primeiros textos pré-cristãos (FOUCAULT, 2009, p. 296), o filósofo procura compreender, a partir de uma multiplicidade de significações e de usos do termo, o vasto campo de experiências - relativo os domínios da filosofia, da espiritualidade e da vida política e social - ao qual a noção encontrou-se vinculada na Antiguidade.

O tema da parrhesia - termo que pode ser traduzido pelas expressões "franco-falar", "coragem da verdade" ou "dizer-verdadeiro" - não chega a Foucault casualmente. É no interior da problematização histórica do preceito filosófico-moral do "cuidado de si" nas culturas clássica e helenística, iniciada no curso $A$ hermenêutica do sujeito (FOUCAULT, 2004), que o pensador encontrará, em toda sua 
riqueza e complexidade de significados, a noção de parrhesia. De difícil apreensão, ela será objeto do estudo de Foucault pela primeira vez ainda no curso de 1982. Em linhas gerais, tratava-se ali de caracterizar a parrhesia como o franco-falar no contexto da direção de existência entre os antigos, sendo apresentada, então, como a palavra verdadeira proferida pelo mestre que visava a provocar no discípulo as reações que o levariam à prática do cuidado de si. Daí as distinções iniciais, que têm lugar no curso de 1982, entre a parrhesia e as formas de discurso consistentes na lisonja e na retórica. Diferentemente dessas formas discursivas, a parrhesia do mestre tinha por finalidade provocar o movimento pessoal do discípulo que o conduziria à conquista da autonomia.

Em Le gouvernement de soi et des autres (FOUCAULT, 2008), curso de 1983, Foucault estudará a parrhesia enquanto a expressão pública e arriscada de uma convicção própria do sujeito que se encontra ontologicamente engajado no ato de enunciação da verdade (GROS, 2008, p. 351). Trata-se, portanto, de uma problematização histórica da "parrhesia política" que, para o filósofo, compreenderá na Antiguidade duas formas principais. De um lado, ela terá a forma da palavra verdadeira proferida pelo cidadão que se dirige ao conjunto dos cidadãos reunidos na assembleia, a fim de convencê-los de sua concepção acerca do interesse comum. Foucault designará essa forma como "parrhesia democrática". De outro lado, ela terá a forma da palavra verdadeira proferida pelo filósofo, que, em particular, se endereça ao governante a fim de incitá-lo a bem dirigir a si mesmo, de tal modo que possa bem dirigir a cidade. A essa forma Foucault chamará "parrhesia autocrática" (GROS, 2008, p. 352). As cinco primeiras aulas do curso serão dedicadas ao estudo da parrhesia democrática e se apoiam na interpretação de dois conjuntos de textos: as tragédias de Eurípides - em especial Íon (1962) - e os discursos de Péricles proferidos aos cidadãos de Atenas, relatados por Tucídides em sua Guerra do Peloponeso (1964). As cinco aulas restantes, que se dedicam ao estudo da parrhesia do filósofo que se dirige ao Príncipe, a parésia autocrática, terão como ponto de apoio principal a análise das Cartas de Platão, em especial a carta VII, bem como dos diálogos Apologia de Sócrates, Fedro e Górgias. 
Esse estudo, realizado no curso de 1983, associado àquele que corresponde ao curso do ano seguinte - Le courage de la vérité (FOUCAULT, 2009) - representa, em nosso entender, a emergência de um importante lugar de atualidade no pensamento de Michel Foucault. Esse lugar de atualidade consiste na abordagem do tema da democracia, privilegiando-se suas implicações com o dizer-verdadeiro. Ainda que estritamente referido à democracia antiga, o estudo empreendido por Foucault acerca do vínculo problemático entre a democracia dos antigos e a parrhesia parece indicar aberturas para uma reflexão atual acerca do tema da democracia. Por certo, para ser efetuada rigorosamente, tal reflexão deveria considerar as inúmeras mediações histórico-conceituais entre aquilo a que designamos modernamente democracia e a democracia antiga. ${ }^{1}$ Não realizaremos essas mediações no âmbito circunscrito deste artigo, uma vez que nos propomos tão somente a indicar, nas análises de Foucault sobre a democracia grega, o importante aspecto ressaltado pelo filósofo consistente no liame complexo que, no contexto daquela, unia a prática democrática e o discurso de verdade. Perante os inúmeros modelos ético-políticos contemporâneos da democracia - indicativos da diversidade, dos limites e da urgência de um pensamento atual sobre o tema - sugerimos um recuo à questão da democracia na Antiguidade, deixando-nos guiar pelas análises de Foucault e por sua percepção acerca da relevância de considerá-la referida ao problema central do dizer-verdadeiro. Talvez essas análises, por uma via própria e em geral distinta daquela dos principais modelos teóricos consolidados, possam sugerir novas frentes para uma reflexão acerca de dimensões fundamentais da democracia no presente.

Assim, centrando-nos apenas nas aulas iniciais do curso Le gouvernement de soi et des autres, procuraremos indicar a via pela qual

\footnotetext{
1 Referimo-nos aqui à necessidade de distinção conceitual e histórica entre a democracia antiga e a democracia moderna ou, ainda, entre as diversas concepções que decorrem da noção moderna de democracia, daquela que concerne à democracia antiga. Como referência inicial e, ao mesmo tempo, essencial a esta tarefa teórica, cabe citar o conhecido discurso Da liberdade dos Antigos comparada à dos Modernos, proferido por Benjamin Constant no início do século XIX (CONSTANT, B. De la liberte chez les modernes. Paris: Hachette, 1980). Limitamo-nos a indicar essa referência primeira, alertando o leitor, entretanto, para 0 vasto campo teórico-conceitual que separa e distingue a democracia antiga das significações que correspondem atualmente ao termo "democracia".
}

Rev. Filos., Aurora, Curitiba, v. 23, n. 32, p. 17-30, jan./jun. 2011 
Foucault chega ao tema da democracia e o problematiza relativamente à noção de parrhesia.

Conforme indicado acima, a análise da parrhesia democrática efetuada no curso de 1983 se dá, em um primeiro momento, a partir da interpretação do Íon de Eurípides (FOUCAULT, 2008, p. 71-145). Apoiando-se em uma longa análise da tragédia - que se estende pelas aulas de 19 de janeiro, 26 de janeiro e em parte da primeira hora da aula de 2 de fevereiro do curso de 1983 -, Foucault aponta para aquilo que entende ser uma circularidade essencial existente entre a democracia antiga e a parrhesia. Em decorrência também de seu esforço interpretativo do texto da tragédia, conclui que a parrhesia antiga - não consistindo apenas no direito constitucional de tomar a palavra na cidade democrática (esse direito era chamado de isegoria), mas sendo a forma do dizer-verdadeiro livre e corajoso de alguns, que tomavam a palavra para bem dirigir a cidade, com todos os riscos que isso poderia acarretar - remetia ao conjunto dos problemas relativos ao exercício efetivo do poder (jogo político) que tinha lugar na cidade democrática. De um lado, portanto, uma necessária circularidade entre a democracia e a parrhesia; de outro, um apelo recíproco e também necessário, evidenciado pela prática da parrhesia, entre a democracia e o jogo político. Seriam essas, segundo nos parece, as principais conclusões que decorrem da análise realizada por Foucault da tragédia.

Ao final da primeira hora da aula de 2 de fevereiro, tem lugar a referência a outras tragédias de Eurípides (FOUCAULT, 2008, p. 147155) nas quais o tema da parrhesia também estaria presente. Foucault utiliza-se dessa referência para dar início ao desenvolvimento do tema a que chamará de "'vínculo problemático' existente entre a parrhesia e a democracia. Em suas palavras, "o vínculo parrêsia/democracia é um vínculo problemático, um vínculo difícil, um vínculo perigoso" (FOUCAULT, 2008, p. 155). Se no Íon encontrávamos como que o momento da fundação mítica da parrhesia democrática em Atenas, os outros textos de Eurípides analisados poderão revelar algumas das ambiguidades da implicação entre a democracia antiga e o dizer-verdadeiro. Assim se passa, por exemplo, com a tragédia Orestes. Em Orestes, segundo Foucault (2008, p. 155), o personagem que dá nome 
à tragédia teria sido condenado à morte, perante o tribunal composto pela assembleia dos cidadãos, porque em seu julgamento “a vitória teria sido dada ao mau orador, àquele que fazia uso de uma parrhesia não-instruída, de uma parrhesia não indexada ao logos de razão e de verdade". Para Foucault, a peça revelaria, então, um perfil sombrio da parrhesia, pondo à luz as ambiguidades entre o dizer-verdadeiro na cidade e a sua estrutura democrática.

É justamente para tratar mais profundamente do tema do vínculo problemático entre a parrhesia e a democracia que, na segunda hora da aula de 2 de fevereiro do curso de 1983, Foucault (2008, p. 157158) proporá uma esclarecedora caracterização - ainda que esquemática - da parrhesia.

Imaginemos a parrhesia como um domínio delimitado pelos quatro lados de um retângulo. Ela seria, portanto, o âmbito circunscrito pelos lados determinados pela união de quatro vértices. Um desses vértices seria a própria democracia, compreendida como a igualdade de todos os cidadãos e a liberdade de cada um deles para falar e participar das decisões comuns. Esse vértice, segundo Foucault, seria como que a "condição formal" da parrhesia. O segundo dos quatro vértices seria aquele do jogo político, uma vez que consiste na ascendência daqueles que, tomando a palavra diante dos outros, fazem-se ouvir, persuadem, dirigem e exercem efetivamente o comando. Esse vértice seria como que a "condição de fato" da parrhesia. O terceiro vértice é aquele do logos. Ele indica que o uso da palavra capaz de exercer um poder sobre a cidade deve ter por referência a verdade. Trata-se, portanto, da "condição de verdade" constitutiva da parrhesia. Por fim, o quarto vértice seria aquele da coragem, pois se refere à necessidade, para aqueles que desejam manter um discurso verdadeiro perante a cidade, em manifestar sua coragem diante dos riscos que podem decorrer da sua palavra. Esta consiste, para Foucault, na "condição moral" da parrhesia.

Assim, esquematicamente, a parrhesia poderia ser compreendida como um domínio ou uma atividade definida a partir de uma condição formal (a democracia), uma condição de fato (o jogo político), uma condição de verdade (o logos) e uma condição moral (a coragem). Essa seria a sua moldura. 
Ora, o vínculo entre a parrhesia e a democracia é problemático ou, ainda, difícil e perigoso - justamente porque ele se concretiza no interior dessa moldura. Concretiza-se no jogo, ao mesmo tempo complexo e frágil, entre as quatro condições que definem a parrhesia. É no interior do jogo entre essas quatro condições, e partir dele, que se produzirá o bom ou o mau funcionamento parrhesia.

Se em Orestes Foucault vislumbrara a prática de uma má parrhesia - ou um exemplo do mau funcionamento dela -, ele encontrará, por sua vez, a expressão do bom funcionamento da parrhesia nos discursos proferidos por Péricles aos cidadãos atenienses, relatados pelo historiador antigo Tucídides, na obra A Guerra do Peloponeso. Ainda que Tucídides não tenha utilizado a palavra parrhesia para referir-se a tais discursos, que têm lugar num período decisivo da Guerra do Peloponeso, Foucault (2008, p. 158) reconhece neles - e reconhece, por conseguinte, na democracia pericleana "um modelo do bom ajuste entre uma politéia democrática e um jogo político inteiramente atravessado por uma parrhesia indexada, ela própria, ao logos de verdade".

Nos livros I e II de A Guerra do Peloponeso, Tucídides “coloca na boca de Péricles", afirma Foucault (2008, p. 158), três grandes discursos: o da guerra, o dos mortos e o da peste. Para o filósofo, independente de sabermos ao certo se tais discursos são de autoria de Péricles ou do próprio Tucídides, eles certamente fornecem um exemplo do bom ajustamento entre a democracia e a parrhesia no final do século $\mathrm{V}$ a.C. Acompanhemos, sucintamente, as considerações de Foucault acerca desses discursos.

O discurso da guerra se dá no momento em que Atenas recebe de Esparta o ultimato para renunciar a algumas de suas importantes conquistas imperiais sobre várias regiões da Grécia. Alguns dos cidadãos consideram a guerra inevitável; outros, porém, pensavam ser possível compatibilizar o ultimato de Esparta e a paz entre as duas cidades. A assembleia dos cidadãos se reúne, então, para deliberar sobre o assunto. Nela, cada um poderá tomar livremente a palavra e manifestar sua posição sobre os rumos que a cidade deve tomar diante daquele impasse. Encontramos aqui, segundo Foucault, 
a representação da condição formal da parrhesia, ou seja, o vértice da democracia (FOUCAULT, 2008, p. 159).

Em dado momento, após todos terem se manifestado, Péricles toma a palavra. Ele é o cidadão mais influente de Atenas, o mais hábil na palavra e na ação. Configura-se aí o segundo vértice do retângulo, o jogo político. Ele concerne ao uso da palavra pelo cidadão cuja ascendência - ascendência pela palavra e pelas ações - ocupa um lugar essencial na prática democrática do contraditório e das deliberações (FOUCAULT, 2008, p. 159). Está indicada, assim, a condição de fato da parrhesia a que se referia Foucault.

Ao dirigir a palavra aos cidadãos, Péricles defende a posição de que Atenas não deveria ceder aos Lacedemônios. Afirma que seu discurso - e a posição por ele defendida - era um discurso com o qual se identificava, pois, assim como os demais conselhos que dera à cidade ao longo de toda a sua carreira política, aquele também se apoiava na verdade. Discurso verdadeiro, portanto, com o qual o enunciador identificava-se inteiramente. Para Foucault, configura-se aqui o terceiro vértice da parrêsia, o logos razoável. Desse modo, no discurso de Péricles sobre a guerra se dá, também, a representação da condição de verdade da parrhesia (FOUCAULT, 2008, p. 160).

Por fim, chegando ao termo de seu discurso, Péricles refere-se ao risco inerente à posição que acabara de defender. Lembra aos atenienses que os acontecimentos podiam não se passar como desejavam e que deviam, portanto, ser solidários, tanto no sucesso de sua empreitada quanto na derrota, pois ele, Péricles, assumia os riscos da posição que defendia, tal como aqueles que aderissem a ela deveriam assumir os riscos da sua decisão. Assim, no cerne desse pacto parresiástico está implicada a virtude da coragem, o quarto vértice da parrhesia. Tem-se, então, a representação da condição moral da parrhesia (cf. FOUCAULT, 2008, p. 160-161).

Desse modo, no discurso de Péricles sobre a guerra, segundo Foucault, encontramos o exemplo da boa parrhesia, uma vez que, no quadro formal da democracia, a ascendência decorrente da habilidade na palavra e na ação permitirá a Péricles manter um discurso de verdade com o qual se identifica, assumindo corajosamente os 
riscos que decorrem de sua enunciação. Dirá Foucault (2008, p. 161): "tal é a boa parrhesia, tal é o bom ajustamento entre a democracia e o dizer-verdadeiro".

Convencida pela palavra de Péricles, a assembleia dos cidadãos não cede às pressões de Esparta e decide por continuar a guerra com a cidade inimiga. Transcorrido um ano dessa importante decisão, no momento em que Atenas enterra seus mortos de guerra e presta a eles homenagem, Péricles proferirá seu segundo discurso, o discurso dos mortos.

Nele, contrariando aquela que provavelmente seria a expectativa da assembleia reunida, não tomará a palavra para fazer o elogio aos mortos pela guerra. Péricles preferirá, ao invés disso, fazer o elogio da cidade. Relembra a todos que Atenas era uma verdadeira democracia, porque, diz ele, a cidade era administrada no interesse geral e não no interesse de uma minoria. Assim é definida a democracia ateniense. Ela não se caracterizava pelo fato de o poder estar ali repartido de maneira exatamente igual entre todos, mas pelo fato de ser administrada no interesse de todos. De algum modo, o discurso de Péricles sobre os mortos, que toma a forma de um discurso sobre o valor da própria cidade, remete novamente ao "grande percurso da parrhesia", segundo Foucault (2008, p. 162), no qual, a partir de uma estrutura democrática, um ascendente legítimo poderá manter corajosamente um discurso verdadeiro, que assegure à cidade tomar suas decisões no interesse de todos.

O terceiro discurso tem lugar quando as derrotas militares de Atenas haviam se multiplicado e a cidade encontrava-se assolada pela peste. Nesse momento, os cidadãos se voltam contra Péricles e o pacto parresiástico de solidariedade - que havia sido proposto por Péricles e celebrado entre todos quando de sua tomada de decisão sobre a continuidade da guerra contra Esparta - está prestes a se romper. Os atenienses haviam até mesmo enviado embaixadores à cidade inimiga para negociarem a rendição de Atenas sem que Péricles o soubesse.

É quando Péricles convoca a assembleia dos cidadãos e nela profere o discurso da peste. Seu conteúdo consiste em relembrar-lhes o vínculo que os unia e que representava a força da cidade. Ele afirmará 
que não se surpreendia com a cólera que dirigiam contra ele. Até conhecia suas razões, mas não podia aceitá-las, pois cabia relembrar-lhes a história de Atenas e o bom funcionamento da sua democracia. E, portanto, cabia também reprovar-lhes, uma vez que perdiam a coragem diante da adversidade e se esqueciam do pacto de solidariedade que os mantinha unidos.

Importa perceber nesse discurso, dirá Foucault (2008, p. 162-163), de que maneira o homem político, que havia proposto o pacto parresiástico, no lugar de agradar seus concidadãos ou tentar derivar para outro a responsabilidade daquilo que se passava, no momento em que o pacto se rompe, volta-se aos cidadãos e não teme reprová-los.

Mais adiante, no mesmo discurso, Péricles se defenderá perante os atenienses, invocando as qualidades do homem político, democrata e parresiasta que, até então, havia sido: ele havia sempre procurado discernir o interesse público e exprimir seu pensamento pela palavra, havia sido devotado à cidade e, por fim, sempre fora inacessível à corrupção (FOUCAULT, 2008, p. 163).

Foucault (2008, p. 163-164) colocará em evidência essas qualidades para indicar novamente, relativamente ao terceiro discurso de Péricles, um exemplo da boa parrhesia. Procurar a verdade, ser capaz de dizê-la, ser dedicado ao interesse geral, ser moralmente íntegro. Somente ao possuir essas quatro qualidades que "o homem político poderá exercer, por meio da parrhesia, a ascendência necessária para que a cidade democrática seja, apesar de tudo, governada".

A fim de prosseguir a explicitação das complexas relações entre a democracia antiga e o dizer-verdadeiro, em oposição à imagem da boa parrhesia fornecida por Tucídides em torno da figura de Péricles, ao final da aula de 2 de fevereiro do curso de 1983, Foucault procurará caracterizar a imagem da má parrhesia, que pode compreendida como o mau ajuste entre a democracia e o jogo político apoiado no dizer-verdadeiro. Irá localizá-la em um período posterior à morte de Péricles, no momento em que Atenas se mostrará uma "cidade na qual o jogo da democracia e o jogo da parrhesia, da democracia e do dizer-verdadeiro não chegam a se combinar e se ajustar de uma maneira que 
seja conveniente e que permita a própria sobrevivência desta democracia" (FOUCAULT, 2008, p. 164).

Uma apresentação dessa Atenas diferente daquela dos tempos de Péricles, bem como da má parrhesia que ali então se manifesta, pode se encontrada, para Foucault, no texto Tratado sobre a paz, de Isócrates.

Nesse Tratado, ao se discutir sobre uma possível paz proposta aos atenienses, Isócrates faz referência à impossibilidade da enunciação do discurso verdadeiro naquela assembleia, bem como à banalização, que tinha lugar ali, do uso público da palavra. Primeiro, em razão da ameaça de expulsão, de ostracismo ou até de morte que pesava sobre a enunciação da verdade quando esta não se conformava aos desejos dos cidadãos. Além disso, não havia ali lugar para a crítica. Isócrates reprova duramente os atenienses, porque estes podiam até mesmo aceitar a crítica a seus erros, desde que essa crítica acontecesse no teatro, sob a forma da comédia. Não toleravam a crítica que teria a forma e a consistência da palavra verdadeira proferida por um orador na assembleia (FOUCAULT, 2008, p. 165). Por fim, ao lado da recusa a toda forma do dizer-verdadeiro na cena política, teria lugar, em Atenas, algo como a imitação do dizer-verdadeiro. Era o discurso demagógico, mantido pelos aduladores, que tomavam a palavra apenas para agradar e obter favores dos demais, sem se preocuparem com aquilo que era útil à cidade.

Tomando o texto de Isócrates e as severas críticas que o pensador antigo endereça aos cidadãos de uma Atenas decadente, Foucault descreve, então, o que consistia a má parrhesia naquele contexto: primeiramente, a ascendência estava comprometida, na medida em que qualquer um podia tomar a palavra, mesmo que não possuísse as qualidades morais de integridade, inteligência e devotamento à cidade que validariam seu discurso; em segundo lugar, aquele que tomava a palavra não o fazia porque tinha convicção de que sua opinião correspondia efetivamente à verdade, mas porque, ao falar aquilo que os demais desejavam ouvir, mantinha-se no lugar protegido da conformidade, ou seja, a verdade e o logos estavam também comprometidos na má parrhesia; por fim, esse falso discurso verdadeiro não tinha por armadura a coragem daquele que era capaz de assumir o risco de sustentar a 
verdade em que acreditava, mas se apoiava na busca da própria segurança e do próprio interesse, o que comprometia finalmente a condição moral da coragem (FOUCAULT, 2008, p. 166-167).

$\mathrm{Na}$ confluência dessas três características, a conclusão de Foucault acerca da má parrhesia é que naquele equivocado ajuste entre democracia e dizer-verdadeiro apagava-se precisamente a diferença indispensável e frágil - introduzida pelo discurso verdadeiro na estrutura democrática (FOUCAULT, 2008, p. 167).

É justamente essa caracterização da má parrhesia que permitirá a Foucault propor, acerca das implicações entre o dizer-verdadeiro e a democracia antiga, ao final da aula de 02 de fevereiro, uma reflexão inquietante.

Ele aponta para aquilo que chama de "dois grandes paradoxos" inerentes às relações entre a democracia e o discurso verdadeiro. O primeiro deles pode ser assim formulado: só pode haver discurso verdadeiro quando há democracia, ou seja, quando existe a condição formal de liberdade e de igualdade que permite a enunciação do discurso de verdade acerca dos negócios da cidade. Esse discurso verdadeiro, por sua vez, introduz na democracia algo que é irredutível à sua estrutura igualitária; ele instalará, no interior da democracia, a diferença. Por outro lado, é esse discurso verdadeiro, na medida em que introduz a diferença no interior da estrutura democrática, que permitirá à democracia subsistir, seguir seu curso através dos revezes e dos conflitos.

Como a outra face desse primeiro paradoxo, viria o segundo: na medida em que o discurso verdadeiro, no interior da democracia, só pode se dar no elemento da disputa e do afrontamento, ele se encontra continuamente ameaçado pela própria democracia. Em outros termos, na democracia - que é condição para o discurso verdadeiro e ao mesmo tempo dele depende para subsistir - está inscrita a ameaça sempre presente da redução do discurso verdadeiro ao silêncio, está inscrita a possibilidade da morte do discurso de verdade (FOUCAULT, 2008, p. 167-168). Em síntese: “não há discurso verdadeiro sem democracia, mas o discurso verdadeiro introduz diferenças na democracia. Não há democracia sem discurso verdadeiro, mas 
a democracia ameaça a própria existência do discurso verdadeiro" (FOUCAULT, 2008, p. 168).

Ao empreender essas análises sobre a boa e a má parrhesia no curso Le gouvernement de soi et des autres, parece-nos configurar-se, conforme afirmávamos no início, uma interessante via para uma reflexão atual acerca da democracia. As análises de Foucault sobre as relações entre a estrutura democrática da cidade antiga e a prática do dizer-verdadeiro sugerem a consideração acerca do lugar que pode ou deve ocupar a questão da verdade - ou, mais precisamente, do discurso de verdade - nas formas que assume atualmente a democracia. Tomada a sério tal sugestão, caber-nos-ia perguntar em que medida aqueles paradoxos identificados por Foucault, relativamente à democracia dos antigos em sua relação com o problema da verdade, ainda seriam pertinentes para pensarmos nos limites, assim como nas possibilidades e desafios colocados hoje à democracia. Em termos mais amplos, caberia perguntar em que medida o campo dos problemas relativamente ao qual costumamos considerar a democracia - como, por exemplo, nas palavras de Foucault (2008, p. 168), o problema da distribuição do poder, da autonomia de cada um no exercício do poder, o problema da transparência e da opacidade, o problema da relação entre a sociedade civil e o Estado - não deveria ser ampliado com essa outra questão, fundamental à democracia antiga, e que talvez continue a ser fundamental na atualidade, que consiste no vínculo necessário, difícil, paradoxal entre a democracia e o dizer-verdadeiro.

\section{Referências}

CONSTANT, B. De la liberte chez les modernes. Paris: Hachette, 1980.

EURIPIDE. Ion, in: EURIPIDE. Tragédies complètes I. Paris: Gallimard, 1962.

FOUCAULT, M. A hermenêutica do sujeito. Tradução de Márcio Alves da Fonseca e Salma Tannus Muchail. São Paulo: Martins Fontes, 2004. 
FOUCAULT, M. Le gouvernement de soi et des autres. Cours au Collège de France. 1982-1983. Paris: Gallimard; Seuil, 2008.

FOUCAULT, M. Le courage de la vérité. Cours au Collège de France. 1984. Paris: Gallimard; Seuil, 2009.

GROS, F. Situation du cours. In: FOUCAULT, M. Le gouvernement de soi et des autres. Cours au Collège de France. 1982-1983. Paris: Gallimard; Seuil, 2008, p. 347-361.

THUCYDIDE. La guerre du peloponnese. Paris: Gallimard, 1964.

Recebido: 16/09/2010

Received: 09/16/2010

Aprovado: 25/11/2010

Approved: 11/25/2010 